\title{
Ottillie Hammes: pioneira da enfermagem catarinense
}

\author{
Ottillie Hammes: a nursing pioneer in Santa Catarina, Brazil
}

Ottillie Hammes: pionera de la enfermería de Santa Catarina, Brasil

\author{
Miriam Süsskind Borenstein', Maria Itayra Padilha', \\ Ana Rosete Maia', Eliani Costa', Vitória Regina Petters Gregório', Ana Maria Koerich Espíndola' \\ 'Universidade Federal de Santa Catarina. Departamento de Enfermagem. \\ Grupo de Estudos de História do Conhecimento da Enfermagem (GEHCE). Florianópolis, SC
}

Submissão: $18 / 08 / 2008$

Aprovação: 03/02/2009

\section{RESUMO}

Trata-se de um estudo sócio-histórico cujo objetivo foi revelar a trajetória profissional de Ottillie Hammes, apresentar alguns traços de sua biografia e analisar sua contribuição para a profissão da enfermagem em Santa Catarina. Na coleta de dados foram realizadas entrevistas e utilizadas outras fontes documentais. Os dados foram categorizados utilizando-se análise de conteúdo e com base no referencial foucaultiano. Os resultados evidenciaram Que Ottillie Hammes provocou mudanças expressivas na enfermagem catarinense, em conseQüência da criação da Escola de Auxiliares de Enfermagem; da Associação Brasileira de Enfermagem - SC e do estímulo a promulgação da Lei Que possibilitou o enQuadramento do enfermeiro na categoria técnica e científica, com conseQüente desenvolvimento da profissão e melhoria da assistência prestada à população.

Descritores: História da enfermagem; Memória; Biografia.

\section{ABSTRACT}

This is a socio-historic study that aimed at revealing Ottillie Hammes' professional trajectory, to present some of her biography traces and analyze her contribution for nursing profession in Santa Catarina, Brazil. During the data collection, interviews were made and documentary sources were utilized. Data was categorized according to content analysis and and also according Foucault's approach. The results demonstrated that Ottillie Hammes caused expressive change in Santa Catarina's nursing, due to the Nursing Auxiliaries School funded in Florianópolis; of the Brazilian Nursing Association - Santa Catarina's Section; the creation and the incentive to the approval of the Law that made the nurse's engaging on the scientific - technician category, increasing the development of the profession and improving the assistance provided to the population.

Descriptors: Nursing history; Memory; Biography.

\section{RESUMEN}

Tratase de un estudio socio-histórico, cuyo objetivo fue revelar la trayectoria profesional de Ottillie Hammes, presentar algunos aspectos de su biografía y analizar su contribución para la profesión de enfermería en el Estado de Santa Catarina - Brasil. Para la recolección de los datos fueron realizadas entrevistas con Ottillie Hammes y utilizadas fuentes documentales. Los datos fueron categorizados de acuerdo con analise del contenido e analizados con base en referencial Foucaultiano. Los resultados evidenciaron Que la Ottillie Hammes provocó mudanzas expresivas en la enfermería catarinense, en consecuencia de la creación de escuela de auxiliares de enfermería en Florianópolis; de la Asociación Brasilera de Enfermería - Sección Santa Catarina y del estimulo a la promulgación de la ley No. $3175 / 63$, la cual posibilitó la inclusión del enfermero en la categoría Técnico - Científica, propiciando así el desarrollo de esa profesión y el mejoramiento de la asistencia prestada a la población.

Descriptores: Historia de la enfermeria; Memoria; Biografia. 


\section{INTRODUÇÃO}

Geralmente a decisão de escrever sobre um determinado sujeito ou objeto acontece em decorrência da importância Que tanto um Quanto outro, possa ter causado em nossa vida pessoal ou profissional. Na década de 90, o Grupo de Estudos de História do Conhecimento da Enfermagem (GEHCE), vinculado ao Programa de Pós Graduação em Enfermagem da Universidade Federal de Santa Catarina (PEN/UFSC) ao procurar conhecer/investigar sobre a História da Enfermagem no Estado de Santa Catarina, teve a oportunidade de conhecer algumas enfermeiras "excepcionais"(1). Muitas destas, haviam se doado Quase Que integralmente à profissão, fazendo com Que a mesma pudesse ser reconhecida num Estado onde ainda, não havia Escolas de Graduação em Enfermagem, nem de Auxiliares, muito menos o reconhecimento da profissão. Uma dessas enfermeiras, particularmente chamou atenção, conhecida como religiosa de "Irmã Cacilda", por ter impregnado na Enfermagem da época, o profissionalismo. Seu nome de nascimento é Ottillie Hammes.

Esse estudo tem como objetivo historicizar o processo de formação profissional de Ottillie Hames, revelar alguns traços de sua biografia e analisar sua contribuição como a primeira enfermeira Que criou importantes instituições relacionadas à Enfermagem no Estado de Santa Catarina. Trata-se de um estudo importante, pois pretende ampliar o conhecimento acerca da História da enfermagem catarinense, e desvelar a vida de uma de suas pioneiras, Que muito contribuiu para a profissão, provocando mudanças, com implicações diretas na assistência e no ensino da enfermagem.

\section{METODOLOGIA}

Trata-se de uma pesquisa Qualitativa com abordagem sócio-histórica, cujos dados foram obtidos através de inúmeras entrevistas realizadas com a própria Ottillie Hammes, nos anos de 2001, 2004 e 2007. As entrevistas encontram-se arQuivadas na sede do GEHCE. Para realização das entrevistas, foi utilizado o método de História Oral $(\mathrm{HO})^{(2)}$. Além disso, foram utilizadas outras fontes documentais como: dissertações, teses, livros, relatórios, artigos publicados em revistas e fotografias.

A pesquisa foi norteada pelos princípios da Resolução 196/96 do Conselho Nacional de Saúde (CNS) ${ }^{(3)}$, tendo sido aprovada pelo Comitê de Ética da UFSC em 17/12/2001, com o Parecer n 148/ 2001. A entrevistada foi orientada sobre o direito participar ou não da pesquisa, tendo concordado e assinado o Termo de Consentimento Livre e Esclarecido. Os dados foram analisados com base no referencial Foucaultiano ${ }^{(4)}$, utilizando-se do método de análise de conteúdo ${ }^{(5)} \mathrm{e}$ foram estabelecidas as seguintes categorias de análise: o nascimento e sua criação; a formação em enfermagem; e a vida profissional: contribuições e implicações para a enfermagem catarinense.

\section{RESULTADOS}

\section{O Nascimento e sua Criação}

Ottilllie Hammes nasceu em Santa Cruz do Sul, no Rio Grande do Sul (RS), em 23 de julho de 1929. Viveu grande parte de sua infância em sua cidade natal, junto com seus pais, Leopoldo Alberto Hammes e Maria Saussen Hammes, e treze irmãos. Era a sexta filha, num universo constituído por sete mulheres e sete homens. Realizou seus estudos primários na Escola Comunitária de São Pedro. Em 1939 (início da 2a . Guerra Mundial), interrompeu seus estudos, pois o Governo Federal proibiu Que os imigrantes alemães e seus descendentes, estudassem, utilizando-se da língua germânica.

Da infância referiu ter "boas e doces recordações", especialmente das brincadeiras realizadas em companhia de seus irmãos, primos e vizinhos. Aos 13 anos, após ter realizado a Primeira Eucaristia, passou a apresentar interesse pela vida religiosa, tendo sido influenciada pelo padre, Que atuava na comunidade onde residia. $\mathrm{Na}$ época, era comum Que tanto famílias alemãs, como às de origem italiana, tivessem pelo menos um dos seus filhos Que seguisse a vida religiosa, tornando-se padre ou freira ${ }^{(6)}$.

A idéia, de se tornar religiosa, serviu como mola propulsora para Que se transferisse em 1944, para Arroio do Meio/RS. Nessa cidade, passou a estudar no Colégio São Miguel da Congregação Divina Providência, preparando-se para o Curso Ginasial (atual ensino fundamental), onde permaneceu por dois anos. Em 1946, foi para Florianópolis/SC, estudar no Colégio Coração de Jesus, de propriedade da Congregação Divina Providência. Nessa escola, concluiu o Ginásio, e na Congregação, o Aspirantado. Em 8 de Janeiro de 1949 entrou definitivamente para a vida religiosa, e a partir daí passou a chamar-se Irmã Cacilda.

No segundo ano de noviciado, Irmã Cacilda passou atuar em uma escola primária, na cidade de Laguna/SC (1951 a 1952). Embora não tivesse sido consultada, era comum, e ainda hoje ocorre, Que nas instituições religiosas, assim como nas prisões e exércitos, os indivíduos não possuíssem o direito de escolha, apenas o de receberem ordens superiores, sem discussão $0^{(4)}$. Eram ordens provenientes da Superiora da Congregação. As irmãs Que não se submetiam, eram prontamente desligadas. Estava diretamente relacionado aos três votos (pobreza, castidade e obediência) Que assumiam, ao ingressar na carreira religiosa. $\mathrm{Na}$ época, havia uma obediência cega $^{(7)}$.

A partir da década de 50, a direção da Congregação Divina Providência passou a se preocupar com a situação dos Hospitais, onde prestavam serviços. Era uma época, em que as religiosas atuavam em vários hospitais na Grande Florianópolis e no interior do Estado. Trabalhavam tanto nos serviços gerais, como em atividades administrativas, e principalmente na enfermagem. Esta última, era constituída por práticos de enfermagem, atendentes e "enfermeiras" formadas na Alemanha (mas sem revalidação/ reconhecimento do diploma no Brasil).

$\mathrm{Na}$ realidade, era um serviço onde trabalhavam pessoas Que não tinham preparo técnico específico, e Que faziam sua formação no cotidiano do trabalho. Isso acontecia tanto com pessoal religioso, como leigo, e era comum nas inúmeras instituições de saúde do país, tendo sido amplamente divulgada por autores que analisaram o período ${ }^{(8-9)}$.

Na década de 50, gradativamente, passou a ocorrer uma modificação na estrutura dos hospitais brasileiros. Estes começaram a se especializar e a utilizar novos equipamentos importados, necessitando de pessoal Qualificado para atuar nos hospitais e a enfermagem. No período, começam a ser construídos os primeiros hospitais universitários. A formação de auxiliares de enfermagem, Que já havia sido iniciada em 1936, se intensifica em 1949 , ocorrendo uma ampliação na formação de novos profissionais, para 
Que pudessem atuar no campo hospitalar ${ }^{(10)}$.

No bojo dessa situação, e considerando as especificidades das instituições hospitalares e os riscos a Que poderiam causar, em detrimento de uma mão de obra não Qualificada, a Congregação Divina Providência, resolveu investir na formação das irmãs como enfermeiras. Irmã Cacilda foi então designada pela Congregação para fazer o Curso de Graduação em Enfermagem na Escola Luisa Marillac, no Rio de Janeiro, da Congregação Filhas da Caridade (Irmãs Vicentinas - São Vicente de Paulo) ${ }^{(9)}$.

\section{A Formação em Enfermagem}

Em 1953, antes de seguir de navio para o Rio de Janeiro, fez um pequeno "estágio" no Hospital de Caridade (Florianópolis/SC), por determinação da Superiora. A finalidade, era conhecer o trabalho da Enfermagem. Segundo ela, a experiência foi "um horror". Ficou extremamente "apavorada" com o Que viu e a maneira como foi orientada. Afirma Que saiu da instituição com a idéia de nunca mais voltaria a entrar num hospital para trabalhar.

No entanto, não tendo direito de escolha, e nem certeza que a enfermagem era a melhor profissão para si, rumou para a formação. Para ingressar no Curso, fez um pequeno teste, "uma espécie de vestibular”. O curso de Graduação em Enfermagem tinha duração de três anos intensivos, com apenas dois meses de férias. As aulas eram teóricas e práticas. Pela manhã, ocorriam os estágios nas instituições de saúde, e à tarde as aulas teóricas. Nos dois últimos anos do curso, realizavam estágios no plantão noturno. Os estágios eram ministrados por professoras, em sua maioria religiosas. Os conteúdos teóricos relacionados com anatomia, fisiologia, patologia, entre outros, eram ministrados por médicos, e Quando eram específicos da profissão, pelas enfermeiras. Havia ainda, professores de outras áreas, Que ministravam os conhecimentos específicos (biologia, bioquímica, farmacologia, psicologia e sociologia).

A Escola possuía salas de aulas, sala para a troca de roupas e para as refeições. A formação estudantil tinha uma natureza e filosofia cristã, porQue era uma Escola da Congregação das Irmãs Vicentinas.

No Que se refere às relações entre alunas e professores, estas eram cerimoniosas. Embora tivessem uma relação amigável, as professoras eram muito exigentes, o conhecimento e os procedimentos eram realizados de forma detalhada e exaustiva. Estes eram acompanhados passo a passo, em suas minúcias, com controle, tanto em termos de organização do material, do ambiente, como na relação estabelecida com o paciente e na operacionalização do cuidado prestado ${ }^{(4)}$

Esta sucessão de etapas, estavam diretamente relacionadas com a disciplina ${ }^{(4)}$. Esta apresenta características comuns, como o controle da atividade, Quando o interesse se dá, não só no resultado final da ação, mas no seu desenvolvimento. Este controle tem o rigor do tempo; da elaboração temporal do ato; da correlação do corpo e dos gestos; da articulação corpo objeto e da utilização exaustiva do indivíduo.

A filosofia da época era permeada por uma dura realidade, onde a formação da enfermeira se dava através dos conhecimentos teóricopráticos associados a uma intensa disciplina, uma vez que a Escola Luisa de Marillac, além de ser uma instituição religiosa, seguia rigidamente as normas preconizadas pelo Sistema Nightingale Que foi implantado inicialmente na primeira Escola de Enfermagem na Inglaterra, em 1860. Portanto, a Enfermagem mantinha uma rígida disciplina e as alunas não tinham como fugir dessa "dura realidade"(9,12).

Durante o curso, a turma, Que era constituída por dezessete alunas (entre leigas e religiosas), de diferentes regiões do país, na faixa etária compreendida entre 20 a 30 anos, teve experiências das mais diversas, tanto nos hospitais, como nos demais serviços de saúde do Rio de Janeiro.

Com todas as dificuldades da época, a Irmã Cacilda teve êxito, e a formatura ocorreu em 17 de março de 1956, Quando finalmente retornou para Florianópolis.

\section{A Vida Profissional: Contribuições e Implicações para a Enfermagem Catarinense}

Ao retornar do Rio de Janeiro, em março de 1956, a Irmã Cacilda passou a trabalhar na Maternidade Carmela Dutra. Tratava-se de uma instituição modelar em termos estruturais e administrativos para a capital do Estado catarinense. Construída pelo então governador Irineu Bornhausen (foi prefeito de Itajaí, governador de Santa Catarina de 31 de janeiro de 1951 a 31 de janeiro de 1956 e senador de 1959 a 1967), a Maternidade possuía 64 leitos. Irmã Cacilda era a única enfermeira, onde até então só havia atendentes de enfermagem e parteiras. Estas últimas faziam o Curso de Parteiras na Maternidade Carlos Corrêa, durante dois anos ${ }^{(13)}$. Por ser uma única enfermeira nesta instituição, era a responsável pela supervisão geral, execução de cuidados mais complexos e treinamento de atendentes. Segundo ela, "era pau para toda obra" (atuava no berçário, sala de parto, sala de cirurgia, entre outros)

No seu retorno como enfermeira, sentia-se vibrante, conforme suas palavras: "vim com todo vapor, mas aí foi uma decepção assim dos infernos". O Curso de Enfermagem na Escola Luisa de Marillac havia sido puxado. As professoras eram muito exigentes e as alunas muito cobradas. Em Florianópolis, Irmã Cacilda teve que se confrontar com "um outro mundo".

"Um determinado dia, Quando estava prontinha para ir trabalhar, a assistente da Madre Superiora, referiu 'trabalha direitinho, mas não precisa fazer tudo o Que aprendeu' Aquilo foi um choque, ai eu pensei comigo 'uma palhaçada, por que me mandaram estudar tanto?'. Depois descobri, Que se eu Quisesse fazer tudo como havia aprendido, as dificuldades seriam imensas. Resultariam em conflitos".

Através dessas falas, observa-se a submissão, a docilidade. A Maternidade apesar de modelar, talvez ainda não tivesse as condições suficientes e necessárias para implementar uma assistência de enfermagem compatível com os moldes da Escola Nightingale.

Florianópolis, na década de 50, caracterizava-se como uma comunidade cuja base econômia havia se mantido Quase inalterada, desde o final do século XIX. A situação começou a se modificar somente após a Segunda Guerra Mundial, especialmente a partir dos anos 60, Quando ocorreu um surto modernizante, em decorrência do Plano de Obras e Equipamentos (1956-1960), havendo a criação de várias instituições, entre elas, a Universidade Federal de Santa Catarina (UFSC) e a Eletrosul, entre outros ${ }^{(14)}$.

\footnotetext{
${ }^{a}$ Borenstein MS, entrevistadora. Cacilda Hammes [entrevistada]. Florianópolis: GEHCE/UFSC; 200I, 2004, 2007. 3 fitas cassete (180min). Entrevistas concedidas ao acervo do Grupo de Estudos de História do Conhecimento da Enfermagem, Florianópolis (SC): GEHCE/UFSC.
} 
Com relação à Enfermagem ${ }^{(8)}$, como dito anteriormente, era basicamente constituída por pessoas com baixo nível de escolaridade. A situação em Florianópolis, nas décadas de 40, 50 e 60, era muito semelhante as demais cidades brasileiras. Segundo uma das primeiras enfermeiras catarinenses, Que passou a atuar nos serviços de saúde do estado, relatou Que muitas das pessoas Que atuavam na enfermagem nos hospitais em Santa Catarina, eram mal alfabetizados e carentes de formação específica de enfermagem ${ }^{(11)}$.

Os funcionários, pelo pouco conhecimento Que possuíam, submetiam-se às ordens médicas. Quanto às religiosas, estava implícito às mesmas Que deveriam evitar conflitos com superiores, mantendo-se obedientes, dóceis e submissas. Irmã Cacilda não correspondia às exigências do seu meio (Congregação e instituição hospitalar). Em uma de suas falas, revelou: "eu não me submeti, era Questão de consciência. "Eu não podia fazer aquilo diferente do que eu aprendi". Até hoje, aquilo me marcou muito". Seguramente, os problemas criados iam parar nas mãos dela. Ela não era a Madre, era a assistente da Madre. Tinha muito medo. Medo dos problemas. Irmã Cacilda referiu ainda Que: "Quando mais tarde, me mandaram fazer especialização, eu reagi Para Quê? se não posso fazer tudo aQuilo Que eu aprendi? Para Quê aprender mais?" Na verdade o Que havia por trás da realização desse curso, era um modo de separar as integrantes, pois havia se formado um grupinho de pessoas mais conscientes acerca do papel da profissão, da necessidade de fazer as coisas bem feitas, uma enfermagem diferente, do Que havia até então.

Quando foi para a Maternidade, começaram os treinamentos para os atendentes de enfermagem. Segundo ela: "Era o jeito de melhorar a capacitação do pessoal. Todos Queriam fazer os cursos". Irmã Cacilda começou a fazer uma resistência às normas estabelecidas, através de um novo modo de fazer a enfermagem, através do discurso e atitudes. Passou a implementar os relatórios de enfermagem, relacionadas aos doentes e às situações cotidianas.

Irmã Cacilda permaneceu na Maternidade Carmela Dutra até setembro de 1957, Quando foi encarregada pela Divina Providência, de planejar e implementar a criação da primeira Escola de Auxiliares de Enfermagem. A idéia da criação foi do Secretário de Saúde da época, sugerida à Madre Superiora, durante a $\mathrm{I}^{\mathrm{a}}$. Semana de Estudos da Enfermagem realizada em Maio de 1956, em Florianópolis( ${ }^{(1)}$.

Irmã Cacilda passou então a planejar e viabilizar a Escola de Auxiliares de Enfermagem, e ao mesmo tempo, trabalhar no Hospital de Caridade, tendo em vista o número limitado de enfermeiras na Capital e a necessidade de organizar um campo de estágio (setembro de 1957 a fevereiro de 1958).

Quando Irmã Cacilda ingressou no Hospital de Caridade, percebeu Que os funcionários "nada sabiam". Segundo ela: "Não tinha um cristão Que sabia ver a pressão. Os analfabetos faziam injeção". Havia até mesmo, conflitos com os médicos Que, às vezes, em urgências, prescreviam tratamento por telefone, e Irmã Cacilda não admitia.. A partir do seu ingresso na instituição, muitas das rotinas passaram a ser implementadas, e até mesmo os prontuários passaram a ser melhor organizados.

Em 1959, com a criação da Escola de Auxiliares de Enfermagem Madre Benvenutta, Irmã Cacilda assumiu a direção e a função de professora nessa Escola, juntamente com outras enfermeiras religiosas e a enfermeira Flérida Cardoso.

Com base na Lei no. 775/49(10) o Curso de Auxiliares tinha a duração de dezoito meses, com aulas teóricas e estágios supervisionados. Foi considerado um marco na história da enfermagem catarinense, pois em decorrência deste, passaram a ocorrer mudanças substanciais nos serviços existentes [...], exigindo uma constante atualização do seu corpo docente Que passou a participar de cursos, jornadas e congressos promovidos pela Associação Brasileira de Enfermagem (ABEn) ${ }^{(9)}$.

Em decorrência da manutenção de um contato permanente com ABEn Central, as professoras do Curso, começaram a perceber a necessidade de ter em Santa Catarina, uma Secção. Ao Questionarem a Presidente da entidade no Rio de Janeiro, essa informou Que deveriam ter no mínimo, dez enfermeiras no Estado. Ao fazerem uma busca no Serviço Estatístico de Estado, descobriram onze enfermeiras. Em 13 de março de 1962, foi criada a ABEn-Santa Catarina, tendo sido eleita a seguinte Diretoria: Presidente: Irmã Cacilda (Ottillie Hammes), Vice-Presidente: Flérida Goudel Cardoso, I ${ }^{a}$. Secretária: Irmã Maria Rita (Alice Rigo) 2a ${ }^{\text {a }}$ Secretária: Irmã Ligória (Maria Edite Primm), Tesoureira Irmã Romana (Carmela Longo) ${ }^{(10)}$.

A partir de então, as associadas passaram a se reunir regularmente na sede da Escola, à fim de deliberarem sobre as atividades diversas, como divulgação da profissão, tomadas de decisões relacionadas a contratação e demissão do pessoal de enfermagem, e até mesmo, consultorias na construção dos novos hospitais.

Com a criação da ABEn-SC, as associadas perceberam a necessidade de incluir o enfermeiro no nível técnico-científico, pois até então, os salários eram similares às demais categorias de enfermagem (práticos, atendentes e auxiliares) . Isso fez com Que Irmã Cacilda procurasse o Secretário de Saúde da época, e após a explanação ao mesmo, conseguiu depois de um ano de tramitação na Assembléia Legislativa do Estado, Que fosse promulgada a Lei $3.175 / 63^{(15)}$ encuadrando o Enfermeiro nesta categoria, permitindo um salário compatível com sua formação

Em decorrência do trabalho desenvolvido pelas enfermeiras em Florianópolis, esse passou a ser percebido, valorizado e reconhecido pelas autoridades. Durante a construção dos hospitais, Edith Gama Ramos e Governador Celso Ramos, ambos em Florianópolis, estas foram solicitadas a participar, garantindo espaços físicos e gerenciais para a Enfermagem, além de pressionar para a contratação de pessoal Qualificado. A partir daí, começam a vir as primeiras enfermeiras de outros estados, para assumirem a assistência de enfermagem nos hospitais Que passaram a ser criados no Estado(1). Essa foi uma grande coneuista da Qual Irmã Cacilda teve importante participação.

Irmã Cacilda permaneceu na Escola de fevereiro de 1958 a 1964 , Quando foi transferida para o Hospital Infantil Edith Gama Ramos, tendo assumido, por aproximadamente um ano, a Chefia do Serviço de Enfermagem.

Em 1965, Irmã Cacilda retornou ao Rio de Janeiro, onde realizou o Curso de Especialização em Pedagogia Didática Aplicada a Enfermagem Pediátrica, promovido pela Escola Anna Nery, em parceria com a Escola Luisa de Marillac. No seu retorno, passou a integrar novamente à Maternidade Carmela Dutra, no cargo de Chefe do Serviço de Enfermagem, onde permaneceu por dois anos. Embora tivesse realizado o Curso de Especialização em Didática, não foi aproveitada na Escola de Auxiliares de Enfermagem. Parece um contra senso da Congregação. Por Que, então, a Madre encaminhou Irmã Cacilda para o curso? 
Em 1969, Irmã Cacilda é transferida novamente para o Hospital de Caridade, onde assumiu atividades assistenciais. O Hospital, a exemplo de outras instituições de saúde no País, estava se modernizando e passou a se caracterizar como o principal campo de estágio para duas faculdades recém criadas: de Medicina, em 1960 (16), e de Enfermagem, em 1969, vinculadas à Universidade Federal de Santa Catarina.

Em 1973, Irmã Cacilda é transferida novamente pela Congregação, sendo Que desta vez, para o interior do Estado, para atuar no Hospital Nossa Senhora da Conceição, na cidade de Tubarão, em decorrência do Quadro deficiente de enfermeiras. A partir de 1974, Irmã Cacilda começa a se envolver com as Questões sociais, Que vinham acontecendo na América Latina, a partir da realização do Concílio Vaticano II e 2 ${ }^{\text {a }}$. Conferência Episcopal Latino Americana, realizado em 1968, em Medellín, cuja preocupação era com a dolorosa realidade da população pobre desses países, e principalmente do Brasil ${ }^{(17)}$.

$\mathrm{Na}$ mesma época, passa a atuar no Curso Técnico de Enfermagem, criado no Colégio Coração de Jesus, na década de 70. Este curso foi criado, como resultado da política do Governo Federal que implementou a política de criação de inúmeras escolas técnicas no país. Irmã Cacilda permaneceu no Curso por apenas um ano (julho de 1977 a maio de 1978).

Em 1978, na Congregação, Que estava passando por uma crise interna, ocorreu uma ruptura, fazendo com Que um grupo de 58 irmãs se desligassem da Divina Providência e fundassem a Fraternidade Esperança. Nessa nova Ordem, Irmã Cacilda optou por atuar junto a Comunidades carentes (rurais, pesqueiras, periféricas e indígenas).

Nessa mesma época, em 1979, assumiu a Coordenação da Pastoral da Saúde na Conferência Nacional dos Bispos do Brasil, onde passou a implementar a saúde comunitária no Estado de Santa Catarina, desenvolvendo o processo nas várias dioceses. Permaneceu no cargo até dezembro de 1992.

Atualmente, Irmã Cacilda, como membro fundadora da
Fraternidade Esperança, ainda desenvolve trabalhos ligadas a essa instituição, realizando atividades em comunidades pobres e na formação de novas religiosas da própria comunidade.

\section{CONSIDERAÇÕES FINAIS}

A participação de Ottillie Hammes (Irmã Cacilda), como profissional por aproximadamente 40 anos e heroína invisível, contribuiu inegavelmente e de forma muito particular para o desenvolvimento da profissão da Enfermagem em Florianópolis e até mesmo no Estado de Santa Catarina. A profissionalização se fez em primeiro lugar por uma mudança de postura dos profissionais, pois ao se formar e retornar ao Estado, Irmã Cacilda rompeu com normas rigidamente estabelecidas e inadequadas. Estas não estavam de acordo com o ideal da enfermagem.

A criação da primeira Escola de Auxiliares de Enfermagem Madre Benvenutta no Estado, é onde ocorre o primeiro núcleo de profissionais de enfermagem e a formação de enfermeiras, Que passam a construir uma enfermagem diferente de tudo Que até então vinha sendo feito.

Com a criação dessa Escola, da ABEn-SC, e finalmente, com o eneuadramento do Enfermeiro no nível técnico-cientifico, Ottillie Hammes, ou Irmã Cacilda, rompeu com uma enfermagem destituída de um conhecimento formal, técnico consubstanciado, caracterizando-se por ser submissa, dócil e sem princípios firmes, e desenvolveu uma nova imagem da profissão, caracterizada por princípios científicos, éticos e filosóficos. Portanto resistiu e fez uma enfermagem moderna no Estado de Santa Catarina e digna de nota. Por tudo isso e muito mais, pode ser considerada sem sombra de dúvida, um exemplo a ser considerado e seguido.

O reconhecimento pelo seu papel na formação e desenvolvimento da enfermagem catarinense e brasileira pode ser evidenciada nas inúmeras homenagens Que vem recebendo ao longo destes últimos (ABEn, UFSC, Assembléia Legislativa do Estado de Santa Catarina, entre outras).

\section{REFERÊNCIAS}

I. Borenstein MS, Padilha MICS, Caetano TL, Mancia JR. Hilda Anna Krisch: pioneira na enfermagem catarinense - formação e contribuição. Rev Bras Enferm 2004; 57(3): 367-70.

2. Meihy JCSB. Manual de história oral. $4^{\mathrm{a}}$ ed. São Paulo: Edições Loyola; 2002.

3. Ministério da Saúde (BR). Conselho Nacional de Saúde Comissão Nacional de Ética em pesquisa (CONEP). Aprova diretrizes e normas regulamentadoras de pesQuisa envolvendo seres humanos. Resolução 196/96, de 10 de outubro de 1996. Brasília: Ministério da Saúde; 1996.

4. Foucault M. Vigiar e punir: nascimento da prisão. $30^{\mathrm{a}} \mathrm{ed}$. Petrópolis: Vozes; 2005.

5. Bardin L. Análise de conteúdo. Lisboa: Edições 70; 2004.

6. Grossi MP. Jeito de freira. Estudo antropológico num convento de Santa Catarina. Florianópolis: Departamento de Enfermagem, Universidade Federal de Santa Catarina; 1989.

7. Borenstein MS, Padilha MICS. O cotidiano das irmãs enfermeiras num hospital de caridade em Florianópolis na década de 50.

Esc Anna Nery R. Enferm 200 I;5(I): 53-63.

8. Alcântara G. A enfermagem moderna como categoria profissional: obstáculos à sua expansão na sociedade brasileira [tese]. Ribeirão Preto: Escola de Enfermagem de Ribeiro Preto, Universidade de São Paulo; 1963.

9. Borenstein MS. Relações de poder num hospital de caridade: uma visão foucaultiana. Pelotas: UFPel; 2000.

10. Carvalho AC. Associação Brasileira de Enfermagem 1926-1976 - documentário. Braślia: ABEn; 1976.

II. Borenstein MS, Althoff CR, Souza ML. Enfermagem da UFSC: recortes de caminhos construídos e memórias - 1969-1999. Florianópolis: Insular; 1999.

12. Padilha MICS. A mística do silêncio: a enfermagem na Santa Casa de Misericórdia do Rio de Janeiro no século XIX. Pelotas: UFPel; 1998.

13. Canassa NSA. Memórias de parteiras: a trajetória profissional na Maternidade Carmela Dutra (1967-1994) [dissertação]. Florianópolis: Programa de Pós-Graduação em Enfermagem, 
Universidade Federal de Santa Catarina; 2005.

14. Centro de Estudos Cultura e cidadania (BR). Uma cidade numa ilha: relatório sobre os problemas sócio-ambientais da ilha de Santa Catarina. Florianópolis: Insular; 1996.

15. Assembléia Legislativa do Estado de Santa Catarina (BR). Lei n. ${ }^{\circ}$ 3.175, de 25 de janeiro de 1963. Reorganiza a Secretaria de Estado dos Negócios de Saúde Pública e Assistência Social cria e suprime órgãos serviços cargos e funções. Florianópolis; 1963. [citado em 09 ago 2008]. Disponível em: http://
200.192.66.20/ALESC/PesquisaDocumentos.asp.

16. Consoni R. Fundação da Faculdade de Medicina de Santa Catarina: reminiscências \& dados históricos. Florianópolis: UFSC; 2005.

17. Rocha GL. Intervención - Conferencia Episcopal de Brasil. V Conferencia General Del espiscopado Latinoamericano Y Del Caribe. Caribe; 2008. [citado 08 ago 2008]. Disponível em: URL: http://www.cefo/content/view/258/332/ 